\title{
STEAM PRETREATMENT FOR COAL LIQUEFACTION
}

\author{
First Quarterly Report
}

For the Period

26 September 1990 to 31 December 1990

\author{
Roberi A. Graff \\ Valeria Balogh-Nair \\ The City College of CUNY \\ Office of Research Administration \\ New York, NY 10031
}

Work Performed Under USDOE Contract No. DE-AC22-90PC90052

William E. Mckinstry, Program Manager

\section{DISCLAIMER}

This report was prepared as an account of work sponsored by an agency of the United States This report was prepared as an account of work sonernent nor any agency thereof, nor any of their Government. Neither the United States Government nor any agency thereol, nor any of their employees, makes any warranty, express or implied, or assumes information, apparatus, product, or process disclosed, or represents that its use would not infringe priyately owned rights. Referprocess disclosed, or represents that its use would process, or service by trade name, trademark, manufacturer, or otherwise does not necessarily constitute or imply its endorsement, recommendation, or favoring by the United States Government or any agency thereof. The views and opinions of authors expressed herein do not necessarily state or reflect those of the United States Government or any agency thereof. 


\section{ACKNOWLEDGEMENTS}

Substantial contributions to the work described here were made by Graduate Research Assistants Olga E. Ivanenko and Claude Brathwaite and Technicians William Hall, Ivan Oritz, Zhen Rong Xu, and Russell Smith. 


\section{ABSTRACT}

Steam pretreatment is the reaction of coal with steam at temperatures well below those usually used for solubilization. The objective of the proposed work is to test the application of steam pretreatment to coal liquefaction. This quarter, a $300 \mathrm{ml}$ stirred autoclave for liquefaction tests was specified and ordered, procedures for extraction tests were reestablished, and the synthesis of four model compounds was completed. Two of these compounds remain to be purified. 


\section{TABLE OF CONTENTS}

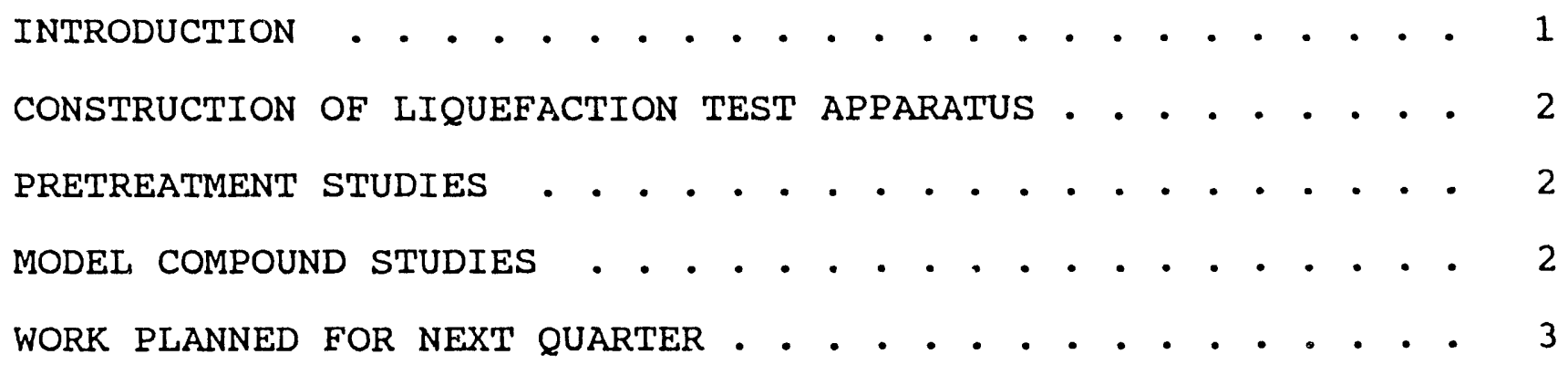




\section{INTRODUCTION}

This is the first quarterly report of a two year program on the application of steam pretreatment to the direct liquefaction of coal. Steam pretreatment is the reaction of coal with steam at temperatures well below those usually used for solubilization.

Steam pretreatment has been shown to be effective in coal pyrolysis. For steam pyrolysis, it has more than doubled the liquid yield, reduced the molecular weight of pyrolysis liquid by 31\%, and increased yields in mild extraction. Studies of pretreated Illinois No. 6 coal indicate that steam reacts with the ether linkages in coal, replacing them with hydroxyl groups. The result is a partially depolymerized coal. The oxygen content of this pretreated coal is $27 \%$ that of the feed.

These results suggest that steam pretreatment prior to solubilization will be beneficial to the coal liquefaction process. It is the objective of this work to test this application. Direct liquefaction of steam pretreated coals will be carried out in a stirred autoclave and the results compared with those from the liquefaction of raw coal.

It is also an objective of this work to develop an improved understanding of the chemistry of steam pretreatment. For this purpose, model compounds will be reacted with steam under the same conditions as used for coal pretreatment and their products analyzed to determine reaction pathways. 


\section{CONSTRUCTION OF LIQUEFACTION TEST APPARATUS}

Autoclave designs offered by the leading manufacturers were examined. A $300 \mathrm{ml}$ stirred autoclave, model DD0300SS03AF16D, manufactured by Autoclave Engineers, Erie,PA, was selected and a purchase order placed with the company.

The pressure vessel will be constructed of Hastelloy $C$ and have a low torque closure with a reusable metallic double delta seal. It will be equipped with a packless magnetic stirrer drive. As a special modification from the standard design, the autoclave will be provided with an external cooling coil of 1/4-inch copper tubing and a custom designed furnace to accommodate this coil. Delivery is expected in January.

\section{PRETREATMENT STUDIES}

Several preliminary extraction tests were carried out using raw Illinois No. 6 coal in order to establish experimental procedures.

\section{MODEL COMPOUND STUDIES}

The first two model compounds, $\alpha$ - and $\beta$-benzylnaphthyl ethers ( 1 and 2), were synthesized in good yields using a modification of the procedure of Maslak and Guthrie [ J. Am. Chem. Soc., 108, 2637 $(1986)]$.

These compounds were prepared by stirring benzyl chloride $(0.879 \mathrm{~g}$, $6.9 \mathrm{mmol})$ with the appropriate naphthol $(1.0 \mathrm{~g}, 6.9 \mathrm{mmol})$ and $\mathrm{K}_{2} \mathrm{CO}_{3}$ $(2.0 \mathrm{~g})$ in $30 \mathrm{ml}$ dry DMF at $25^{\circ} \mathrm{C}$ under a nitrogen atmosphere for 36 hours. The reaction mixture was then poured into a $\mathrm{H}_{2} \mathrm{O} / \mathrm{CH}_{2} \mathrm{Cl}_{2}$ mixture ( $200 \mathrm{ml}$ each). The organic layer was separated and the solvent removed by vacuum. The residue was recrystallized twice from ethanol and checked for purity using thin layer chromatography on hptlc plates. The yields for 1 and 2 were $83 \%$ and $67 \%$ respectively. The products gave melting points and ${ }^{1} \mathrm{H} \mathrm{nmr}$ spectra essentially identical with those reported in the literature. Further purification gave about one gram of each sample with greater than 99\% purity as determined by HPLC.

The second pair of compounds, $\alpha$ - and $\beta$-naphthylmethyl phenyl ethers, was synthesized in good yields following the same rocedure. These compounds are now being purified. 
WORK PLANNED FOR NEXT QUARTER

A selection of coals will be ordered from the Penn State Sample Bank. Procedures for pretreatment will be reestablished and a new procedure suitable for model compounds will be developed. Purification of model compounds will be continued. 

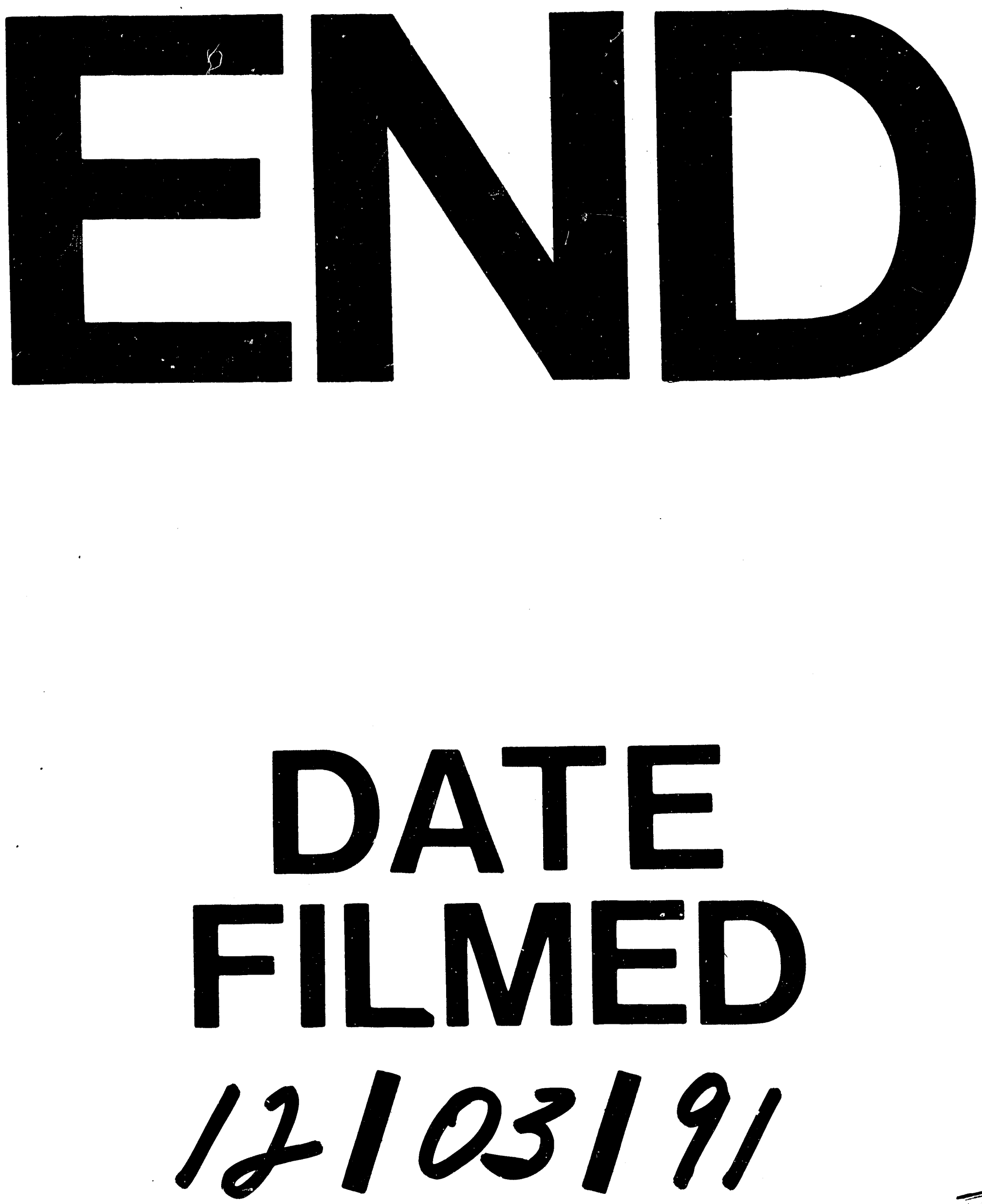

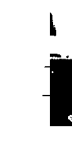


